\title{
Prevalence of Temporomandibular Disorder among Schoolchildren in Jordan
}

\author{
Jihad M Jomhawi ${ }^{1}$, Abdulsalam M Elsamarneh ${ }^{2}$, Ahmad M Hassan ${ }^{3}$
}

\begin{abstract}
Purpose: The purpose of this study was to evaluate the prevalence of temporomandibular disorders (TMDs) in schoolchildren. Materials and methods: In this study a questionnaire taken as part of RDC/TMD of the samples on TMD symptoms. The samples were school students, who were of the age range 15-17 years old $(n=396), 200$ are males and 196 are females. All from eight randomly selected schools. They were asked to answer the questionnaire in their classrooms.

Results: The prevalence of periauricular pain was $29.0 \%$. More males were affected by TMD than females and most of the affected students were of ages 16 and 17 years old. Severe depression occurs in $69.6 \%$ of the affected students with periauricular pain. Periauricular pain resulted in low disability low-intensity pain (grade I) in $64.9 \%$.

Conclusion: Based on the results obtained it can be concluded that: (1) Data obtained from the questionnaire identified a nearly lower percentage of TMD in schoolchildren than most of the studies published in the literature; (2) Comparing with females, males with TMD had a higher disability, depression, and non-specific symptoms with and without pain.

Clinical significance: Temporomandibular disorder in adolescents is relatively high, in addition, the accompanying pain and depression that is high to worsen the condition.

Keywords: Pain, Periauricular, Prevalence, Temporomandibular disorder.

International Journal of Clinical Pediatric Dentistry (2021): 10.5005/jp-journals-10005-1939
\end{abstract}

\section{INTRODUCTION}

The temporomandibular joint (TMJ) is the joint that produces the articulation of the mandibular condyle with the temporal fossa of the temporal bone. The joint includes two compartments separated by a biconcave disc. This joint produces two movements during its function are rotational and transitional; in the rotational movement, the condyle rotates in its position (motionless move), while in the transitional move the condyle with the disc moves anteriorly.

There is increased attention toward temporomandibular disorders (TMDs) in children and adolescents in the past 30 years. When the activity passes the physiological tolerance of an individual, this can produce damage to the TMJ, musculature, or dentition. Temporomandibular disorder was defined in all the past studies; by the presence of one or more signs and symptoms listed in each clinical examination and questionnaire investigation. ${ }^{1}$ Temporomandibular disorder has been clinically characterized by describing signs only or a combination of signs and symptoms. ${ }^{2}$

The American Dental Association (ADA) has suggested the term TMDs; to describe a group of abnormalities that are characterized by: pain in the TMJ, the muscles of mastication, or periauricular area with deviation or limitation in the range of motion of TMJ, also noises in the TMJ during the mandibular function. ${ }^{3}$

The major challenge in identifying TMD rises from its complicated association with other structures of the head, the neck, and the scapular girdle. In addition to the large variety of signs and symptoms associated with TMJ by these structures and vice versa. The importance of epidemiology regarding TMD concerns the understanding of several symptomatic associations and therapeutic strategies, allowing the establishment of prevention and control programs. $^{4}$

Temporomandibular disorder represents a general health problem, and in many situations, if diagnosed too late, it will
${ }^{1}$ Dental Department, Princess Basma Teaching Hospital, Ministry of Health, Irbid, Jordan

${ }^{2}$ Kufer Som Comprehensive Health Center, Ministry of Health, Irbid, Jordan

${ }^{3}$ Private Dental Clinic, Irbid, Jordan

Corresponding Author: Jihad M Jomhawi, Dental Department, Princess Basma Teaching Hospital, Ministry of Health, Irbid, Jordan, Phone: +962777713605, e-mail: jjomhawi@yahoo.com

How to cite this article: Jomhawi JM, Elsamarneh AM, Hassan AM. Prevalence of Temporomandibular Disorder among Schoolchildren in Jordan. Int J Clin Pediatr Dent 2021;14(2): 304-310.

Source of support: Nil

Conflict of interest: None

move into a state of irreversible damage of the intra-capsular TMJ components. ${ }^{1}$ Temporomandibular disorder pain confirmed as a condition of principal public health value with a prevalence of about $10 \%$ in adults. ${ }^{2}$

The etiology of TMDs continues as a subject of debate, particularly concerning the role of occlusion. ${ }^{5}$

It is pleasing to note that the incidence of signs and symptoms usually raised with age. Magnusson et al. studied 119 over 4 years and inscribed a significant rise in signs and symptoms of TMD with age. ${ }^{6}$

The objectives of this study are: (1) to assess the psychosocial condition of TMD, in terms of chronic pain dysfunction (i.e., pain intensity and reliability, and disability), depression, and non-specific physical symptoms. (2) To assess the limitations in the ability to use the jaw. 
This study assessed the prevalence of TMD in schoolchildren in the north of Jordan.

\section{Literature Review}

Some investigators have suggested that oral parafunctions are possible factors in the etiology of TMD in patients with younger age. $^{2}$

To conclude from the outcomes of epidemiological and more new clinical studies, the questionnaire has some advantages. Researchers insisted that it is more trusty than the clinical interview and other methods, as it excludes the expectations and biased opinions of the examiner. A questionnaire tries to promptly identify patients who may have TMD, so helping the dentist to perform a precise diagnosis. ${ }^{7}$

The prevalence of TMD has been broadly studied for diverse populations, e.g., in different cultural regions, environments, and children. Though, the outcomes for older cases have been incompatible: some studies have stated that the frequency of symptoms of TMD was alike for different age groups; others have noticed that it was lower among older cases. ${ }^{8}$

By the end of 1998, there is only one study that described the prevalence of TMD's signs and symptoms among Saudi children aged 3-7 years.

A total of 12 schools of Saudi Arabia, in Farsi's study in 2003, with a total of 1,976 children selected. The prevalence of TMD signs was $20.7 \%$, with the most frequent sign of TMD was joint sounds with a percent of $11.8 \%$. The next most common sign is restricted mouth opening, and its percent was $5.3 \%$. Muscle pain TMJ pain, as well as the deviation in jaw opening, occurred unusually.

Temporomandibular disorder symptoms as described by the parents were apparent in $24.2 \%$ of the answered questionnaires. The most frequent symptoms were a headache with $13.6 \%$ and pain on chewing with $11.1 \%$. The incidence of headache reported as significantly increased in primary compared with permanent dentition. The least common oral parafunction was bruxism with $8.4 \%$, while the most common was nail-biting with $27.7 \%{ }^{1}$

Various studies have investigated the prevalence of TMD and revealed that from 33 to $86 \%$ of the population exhibits at least one sign of TMD, and from 12 to $51 \%$ of the population reported perception of symptoms. ${ }^{9}$

On one hand, Nassif et al.'s study checked history as well as examined the cases that were done on 523 young adult males. The subjects were grouped into four groups ranging from no symptoms or signs to severe symptoms or signs. The overall results showed that $75 \%$ of the subjects had TMD symptoms or signs. Also, it was recommended that the subjects reported to have significantly moderate to severe signs or symptoms should have a comprehensive TMD evaluation to identify if it is recommended to have TMD therapy. ${ }^{10}$

In the study by Nilner et al., the prevalence of TMD in adolescents and children differs extensively in the literature; it could be as high as $90 \%$ with mixed dentition or as low as $16 \%$ in the primary dentition. ${ }^{1}$

On the other hand, cross-sectional studies not done on patients showed that the prevalence has stated that about $33 \%$ have at least one symptom of TMD. Also, about $50-75 \%$ of the studied subjects possess one or more signs of TMD. ${ }^{10}$

Fifty-eight years old peoples' home residents and 44 young samples were examined using a validated and standardized examination method.
Older citizens more often presented objective symptoms of TMD as joint sound on opening with $38 \%$, but rarely suffered from pain, so there is no pain at rest or joint pain and rare muscle pain of $12 \%$. On the opposite, young subjects rarely showed objective symptoms, so joint sounds of $7 \%$ but suffered more frequently from pain; facial with $7 \%$, joint pain with $16 \%$, muscle pain with $25 \%$. In young cases, there is a higher mandibular range of motion. ${ }^{8}$

Two hundred and fifty-four senior dental students (159 males, 95 females), this study of schoolchildren was done to define the prevalence of TMD. In addition, object analysis was performed to find out if there were any differences related to sex in children. The percentage of who has more than four "yes" answers was $5.66 \%$ in males and $15.79 \%$ in females, and the difference between males and females was significant $(p<0.001){ }^{7}$

A total of 140 Indians attending a mobile dental health caravan in Ecuador were examined subjectively and objectively for symptoms and signs of TMD using a manner similar to that used in earlier studies. There was a prevalence of $63 \%$ having at least one sign. ${ }^{9}$

Temporomandibular disorder is a common pain disorder affecting up to $15 \%$ of North American adults, Pain in TMJ or the muscles of mastication are the predominant symptoms of the disorder. Temporomandibular disorder disorders have their highest prevalence among women during their reproduction years. They are one and a half to two times less prevalent in men than in women in the population. ${ }^{11}$ Temporomandibular disorder is now generally considered to be one of the health risks linked to malocclusion. Symptoms and signs of TMD and their association with malocclusion have been less extensively studied in children and adolescents. ${ }^{12} \mathrm{~A}$ raised prevalence of headache and TMJ clicking with age and higher prevalence in girls compared with boys have been declared. ${ }^{13}$ Nilner reported in a review that the prevalence of TMD varied from 12 to $58 \%$ in different epidemiological studies. ${ }^{14}$

The need for stomatognathic treatment in a population of adolescents and young adults has been approved to be $5-27 \%{ }^{13}$

\section{Materials and Methods}

A descriptive cross-sectional study was used to investigate the prevalence of TMD in a group of school students.

A random cluster sample was selected from the Bani Kenanh schools in the north of Jordan that contains 13 male secondary schools while the number of female secondary schools is 19. Four female schools were selected are Kufor Som, Um Qais, Saham, and Kharja schools. And four male schools were selected are Kufor Som, Saham, Malka, Hubras schools with a total of 396 students (196 males and 200 females) with an age range between 15 years and 17 years, and about 10 of the students refused to complete the questionnaire. Only the tenth and first secondary classes were asked to answer a 23-item questionnaire by giving the questionnaire to the students at school and any unclear question has been explained to the students. The questionnaire was translated into the Arabic language by an English specialist with the help of a dentist and then re-translated into the English language again to be sure that its translation to the Arabic language is right. The questions related to sexual activity are omitted because the questions are sensitive and unacceptable in our society. A question related to races was canceled too because the sample was chosen from a rural area and there are no racial differences and the question about the date of birth changed to ask about age in years. The process of collecting data was started by posting a document to the ministry of education. 
The benefit of the questionnaire is that the individual can view the question calmly or that their guardians can help their children. ${ }^{1}$

The questionnaire is a Research Diagnostic Criteria for TMD also named RDC/TMD that has been developed by Doworkin et al. in 1992 to create valid and reliable standardized diagnostic criteria for defining and/or classifying the different types of TMD.

RDC/TMD involves two sections:

Axis I: called the clinical TMD conditions and measures physical findings. Named the pain-related disability and psychological situation that assess the TMD, in terms of depression, chronic pain dysfunction, and unspecific physical symptoms.

Axis II: involve questions about pain-related disability, chronic pain, and a scale of scoring pain with interference of activity from 1 to 10 . So, our concentration was based on Axis II.

\section{Results}

This study included a total of 396 schoolchildren aged between 15 years and 17 years.

The sociodemographic features of the subjects have been described in Table 1. About $12.6 \%$ were 15 years old, where the majority were between 16 years and 17 years old. The proportion of males was similar to that of females. More than $90 \%$ of participants have good to excellent general health, and nearly the same proportion have good to excellent oral health. The prevalence of periauricular pain expressing TMD was $29 \%$.

Table 2 shows how the prevalence of periauricular pain is affected by self-reported oral and general health, as well as

Table 1: The sociodemographic characteristics of participants

\begin{tabular}{|c|c|}
\hline Variables & $N(\%)$ \\
\hline \multicolumn{2}{|l|}{ Age } \\
\hline 15 years & $50(12.6)$ \\
\hline 16 years & $175(44.2)$ \\
\hline 17 years & $171(43.2)$ \\
\hline \multicolumn{2}{|l|}{ Gender } \\
\hline Male & $196(49.5)$ \\
\hline Female & $200(50.5)$ \\
\hline \multicolumn{2}{|l|}{ Class } \\
\hline 10th grade & $201(50.8)$ \\
\hline 11th grade & $195(49.2)$ \\
\hline \multicolumn{2}{|l|}{ General health } \\
\hline Excellent & $155(39.1)$ \\
\hline Very good & $165(41.7)$ \\
\hline Good & $54(13.6)$ \\
\hline Accepted & $14(3.5)$ \\
\hline Bad & $7(1.8)$ \\
\hline \multicolumn{2}{|l|}{ Oral health } \\
\hline Excellent & $117(29.5)$ \\
\hline Very good & $169(42.7)$ \\
\hline Good & $80(20.2)$ \\
\hline Accepted & $19(4.8)$ \\
\hline Bad & $10(2.5)$ \\
\hline \multicolumn{2}{|c|}{ Periauricular pain } \\
\hline Yes & $115(29.0)$ \\
\hline No & $281(71.0)$ \\
\hline
\end{tabular}

sociodemographic characteristics. The prevalence of periauricular pain was dependent on gender, class, and general health. Around $40 \%$ of 15 years old children, $28.2 \%$ of 16 years old children, and $27.4 \%$ of 17 years old children had periauricular pain. About $41.5 \%$ of the males and $17.6 \%$ of females had periauricular pain with a significant difference, observed from the table. Of the students of the tenth class, there was $34 \%$, and from the students of the eleventh class, $24.5 \%$ had periauricular pain.

Disability, depression, pain, and unspecific physical pain with and without the pain of students with periauricular pain described in Table 3; Males had more disability, depression, and unspecific physical symptoms than females. The bulk of students with TMD are grade I, i.e., low disability-low-intensity pain, which represents about $64.9 \%$, while nearly the same majority had severe depression representing $69.6 \%$, this is with significant difference between males and females. Fifty-three percent of students with TMD have severe not specific physical symptoms without pain and $57.4 \%$ have severe not specific physical symptoms with pain. It worth noting that $0 \%$ of the females have high disability-severely limiting pain (grade IV).

Assessment of the limitation of ability to use the jaw in students with periauricular pain depicted in Table 4; showed that the limitations to using the jaw were all more common in males than females with no significance in the differences. It was found that the most common limitation is the jaw pain limit certain activities that represented $51.3 \%$ and stiffness in the jaw with a percent of $46.0 \%$, and headache that represented $45.2 \%$. It should be mentioned that

Table 2: Prevalence of periauricular pain by sociodemographic, general, and oral health

\begin{tabular}{|c|c|c|c|c|}
\hline Variable & Yes N (\%) & No N (\%) & Total N & $p$ value \\
\hline \multicolumn{5}{|l|}{ Age } \\
\hline 15 years & $20(40.0)$ & $30(60.0)$ & 50 & \multirow[t]{3}{*}{0.205} \\
\hline 16 years & $49(28.2)$ & $125(71.8)$ & 174 & \\
\hline 17 years & $46(27.4)$ & $122(72.6)$ & 168 & \\
\hline \multicolumn{5}{|l|}{ Gender } \\
\hline Male & $80(41.5)$ & $113(58.5)$ & 193 & \multirow[t]{2}{*}{0.00} \\
\hline Female & 35 (17.6) & $164(82.4)$ & 199 & \\
\hline \multicolumn{5}{|l|}{ Income } \\
\hline$<250$ & $65(29.0)$ & $159(71.0)$ & 224 & \multirow[t]{2}{*}{0.873} \\
\hline$>250$ & $50(29.8)$ & $118(70.2)$ & 168 & \\
\hline \multicolumn{5}{|l|}{ Class } \\
\hline 10th grade & $68(34.0)$ & $132(66.0)$ & 200 & \multirow[t]{2}{*}{0.038} \\
\hline 11 th grade & $47(24.5)$ & $145(75.5)$ & 192 & \\
\hline \multicolumn{5}{|l|}{ General health } \\
\hline Excellent & $35(22.7)$ & $119(77.3)$ & 154 & \multirow[t]{5}{*}{0.011} \\
\hline Very good & $47(28.7)$ & $117(71.3)$ & 164 & \\
\hline Good & $26(48.1)$ & 28 (51.9) & 54 & \\
\hline Accepted & $5(38.5)$ & $8(61.5)$ & 13 & \\
\hline Bad & $2(28.6)$ & $5(71.4)$ & 7 & \\
\hline \multicolumn{5}{|l|}{ Oral health } \\
\hline Excellent & $28(24.1)$ & 88 (75.9) & 116 & \multirow[t]{5}{*}{0.392} \\
\hline Very good & $51(30.5)$ & $116(69.5)$ & 167 & \\
\hline Good & $29(36.3)$ & $51(63.8)$ & 80 & \\
\hline Accepted & $4(21.1)$ & $15(78.9)$ & 19 & \\
\hline Bad & $3(30.0)$ & $7(70.0)$ & 10 & \\
\hline
\end{tabular}


Table 3: Pain-related disability and psychological status in terms of chronic pain dysfunction, depression, and nonspecific physical symptoms excluding and including pain

\begin{tabular}{|c|c|c|c|c|}
\hline Variable & Male N (\%) & Female N (\%) & Total & $p$ value \\
\hline \multicolumn{5}{|l|}{ Grade } \\
\hline Low-disability-low-intensity pain (grade I) & $50(62.5)$ & $24(70.6)$ & $74(64.9)$ & 0.595 \\
\hline Low-disability-high-intensity pain (grade II) & $11(13.8)$ & $5(14.7)$ & $16(14.0)$ & \\
\hline High-disability-moderately limiting (grade III) & $16(20.0)$ & $5(14.7)$ & $21(18.4)$ & \\
\hline High-disability-severely limiting (grade IV) & $3(3.8)$ & $0(0.0)$ & $3(2.6)$ & \\
\hline \multicolumn{5}{|l|}{ Depression } \\
\hline Normal: & $9(11.3)$ & $3(8.6)$ & $12(10.4)$ & 0.027 \\
\hline Moderate ( $>17 \%$ on population norm) & $21(26.3)$ & $2(5.7)$ & $23(20.0)$ & \\
\hline Severe ( $>19 \%$ on population norm) & $50(62.5)$ & $30(85.7)$ & $80(69.6)$ & \\
\hline \multicolumn{5}{|l|}{ Non-specific physical symptoms exclude pain } \\
\hline Normal: & $18(22.5)$ & $3(8.6)$ & $21(18.3)$ & \\
\hline Moderate (>17 percentile on population norm) & $20(25.0)$ & $13(37.1)$ & $33(28.7)$ & \\
\hline Severe (above 19 percentile on population norm) & $42(52.5)$ & $19(54.3)$ & $61(53.0)$ & \\
\hline \multicolumn{5}{|l|}{ Non-specific physical symptoms include pain } \\
\hline Normal: & $21(26.3)$ & $(14.3)$ & $26(22.6)$ & 0.184 \\
\hline Moderate (>17 percentile on population norm) & $13(16.3)$ & $10(28.6)$ & $23(20.0)$ & \\
\hline Severe (above 19 percentile on population norm) & $46(57.5)$ & $20(57.1)$ & $66(57.4)$ & \\
\hline
\end{tabular}

Table 4: Assessment of the limitation of the ability to use the jaw

\begin{tabular}{llccc}
\hline Category & Male & Female & Total & p value \\
\hline Jaw lock or catch & $20(25.0)$ & $15(42.9)$ & $35(30.4)$ & 0.055 \\
Severe limitation in jaw opening & $11(55.0)$ & $8(53.3)$ & $19(54.3)$ & 0.922 \\
Jaw click or pop/open or close & $14(17.5)$ & $7(20.0)$ & $21(18.3)$ & 0.750 \\
Jaw makes grinding noise & $17(21.3)$ & $3(8.6)$ & $20(17.4)$ & 0.099 \\
Grind or clinch while sleep & $29(36.3)$ & $8(22.9)$ & $37(32.2)$ & 0.157 \\
Grind or clinch at day time & $34(42.5)$ & $10(28.6)$ & $44(38.3)$ & 0.157 \\
Jaw ache or feel stiff & $35(43.8)$ & $18(51.4)$ & $53(46.0)$ & 0.447 \\
Your bite feel uncomfortable & $20(25.0)$ & $14(40.0)$ & $34(29.6)$ & 0.105 \\
Diseases (R. arthritis. SLE) & $17(21.3)$ & $5(14.3)$ & $22(19.1)$ & 0.382 \\
Family history of above diseases & $11(13.8)$ & $5(14.3)$ & $16(13.9)$ & 0.939 \\
Swollen or painful joint & $18(22.5)$ & $5(14.3)$ & $23(20.0)$ & 0.311 \\
Persistent pain one or more years & $7(8.8)$ & $5(14.3)$ & $12(10.4)$ & 0.057 \\
Injury to face or jaw & $21(26.3)$ & $8(22.9)$ & $29(25.2)$ & 0.700 \\
Headaches or migraines & $35(43.8)$ & $17(48.6)$ & $52(45.2)$ & 0.633 \\
Jaw pain limit certain activities & $43(53.8)$ & $16(45.7)$ & $59(51.3)$ & 0.428 \\
Jaw pain limit chewing & $27(62.8)$ & $12(75.0)$ & $39(66.0)$ & 0.378 \\
Jaw pain limit exercising & $19(44.2)$ & $10(62.5)$ & $29(49.2)$ & 0.211 \\
Jaw pain limit drinking & $19(44.2)$ & $8(50.0)$ & $27(45.8)$ & 0.690 \\
Jaw pain limit eat in hard food & $30(69.8)$ & $12(75.0)$ & $42(71.2)$ & 0.693 \\
Jaw pain limit smile and laugh & $22(51.2)$ & $5(31.3)$ & $27(45.8)$ & 0.172 \\
Jaw pain limit clean teeth/face & $22(51.2)$ & $9(56.3)$ & $31(52.5)$ & 0.728 \\
Jaw pain limit yawing & $25(58.1)$ & $9(56.3)$ & $34(57.6)$ & 0.896 \\
Jaw pain limit swallowing & $25(58.1)$ & $6(37.5)$ & $31(52.5)$ & 0.158 \\
Jaw pain limit talking & $22(51.2)$ & $7(43.8)$ & $29(49.2)$ & 0.613 \\
Jaw pain limit usual facial appearance & $22(51.2)$ & $8(50.0)$ & $30(50.8)$ & 0.937 \\
\hline
\end{tabular}

jaw-made grinding noise occurred in $17.4 \%$, clinching during night occurred in $32.2 \%$, and during the day is $38.3 \%$.

In Table 5, average incomes for males and females are (262.8 \pm $200.3)$ and (310.1 \pm 149.5$)$, respectively. The average time of facial pain is $5.1 \pm 2.0$ for males and $3.2 \pm 3.2$ for females, and if pain persists $>1$ year, the mean for males is $1.06 \pm 1.12$, and for females, it is $1.03 \pm 1.26$. When students were asked to rate their facial pain, the intensity of the worst pain, and intensity of the average pain on a graduated scale, the means are $3.5 \pm 2.0,4.0 \pm 2.5$, and $3.3 \pm 2.4$ for males and: $3.1 \pm 2.0,3.3 \pm 2.6$, and $3.1 \pm 2.4$ for females, respectively. 
Table 5: The mean, standard deviation, and $p$ value of the income, characteristics of facial pain, disability, depression, and physical symptoms

\begin{tabular}{lccc}
\hline Variable & Male $($ mean \pm SD) & Female (mean \pm SD) & $p$ value \\
\hline Income & $262.8 \pm 200.3$ & $310.1 \pm 149.5$ & 0.119 \\
How many years facial pain begin & $1.06 \pm 1.12$ & $1.03 \pm 1.26$ & 0.890 \\
How many months facial pain begin & $5.1 \pm 2.0$ & $3.2 \pm 3.2$ & 0.072 \\
Rate your facial pain & $3.5 \pm 2.0$ & $3.1 \pm 2.0$ & 0.199 \\
How intense was your worst pain & $4.0 \pm 2.5$ & $3.3 \pm 2.6$ & 0.162 \\
How intense was your pain (average) & $3.3 \pm 2.4$ & $3.1 \pm 2.4$ & 0.561 \\
Pain keeps you from daily activities & $5.5 \pm 3.4$ & $2.6 \pm 6.2$ & 0.016 \\
How much pain interfere with your usual activities & $3.9 \pm 2.8$ & $2.4 \pm 3.1$ & 0.187 \\
How much facial pain interfere with social activities & $3.5 \pm 2.8$ & $2.7 \pm 3.0$ & 0.564 \\
How much facial pain changeability to work & $3.4 \pm 3.5$ & $3.0 \pm 3.4$ & 0.056 \\
Jaw lock or catch & $1.3 \pm 0.5$ & $1.4 \pm 0.05$ & $1.5 \pm 0.5$ \\
Severe limitation in jaw opening & $1.6 \pm 0.5$ & $31.4 \pm 20.2$ & 0.195 \\
Characteristic pain intensity & $36.8 \pm 21.2$ & $26.9 \pm 27.6$ & 0.106 \\
Disability score & $35.9 \pm 24.5$ & $0.2 \pm 0.7$ & 0.049 \\
Points for disability days & $0.5 \pm 0.6$ & $0.7 \pm 1.1$ & 0.188 \\
Points for disability score & $1.0 \pm 1.0$ & $0.9 \pm 1.4$ & 0.0034 \\
Disability points & $1.5 \pm 1.3$ & $1.9 \pm 0.9$ & 0.005 \\
Depression & $1.4 \pm 0.9$ & $1.3 \pm 0.8$ & 0.365 \\
Non-specific physical symptoms including pain & $1.8 \pm 0.9$ & $1.3 \pm 0.9$ & 0.317 \\
Non-specific physical symptoms excluding pain & $1.1 \pm 1.0$ & & \\
\hline
\end{tabular}

All of the above variables showed insignificance between males and females except for four variables that are pain interfere with student's usual activities, number of disability days, the mean for depression, and the mean for disability points.

\section{Discussion}

The variety of TMD prevalence among different studies has been ascribed to the differences in the ages of different samples, sample size, and composition. ${ }^{1}$ The prevalence of head pain has been investigated widely in medical research and has seldom been connected with the presence of TM disorders in the dental literature. ${ }^{7}$

Farsi reported that the prevalence of TMD among Saudi children was $20.7 \%$. It had been noted that his age group nearly close to that of this study, and the prevalence too. Farsi's study used the questionnaire as well as the clinical examination, but TMD symptoms were described in $24.2 \%$ of the returned questionnaires, which will be closer to the prevalence of this study.

Nekora-Azak proposed that there is a potential link between its TMD pathogenesis and female hormones. The survey of the literature showed that most of the patients treated for TMD are women. $^{15}$

Opposite to other studies, this study showed that males are more affected by TMD than females with a significant $p$ value; this may be related to lower ages or low educational levels. The demand for further studies in Jordan may be essential in this age group and elder once.

Among TMD prevalence studies, the study by Nassif et al. noted that there are positive TMD findings in $69 \%$, including muscle disorders with $23 \%$, joint disorders with $19 \%$, or both with $27 \%{ }^{10}$

In addition, a study by Solberg et al. correlates positively with the study by Schiffman et al. where $65 \%$ of 739 university students had one or more symptoms/signs of TMDs. ${ }^{16,17}$
In this study, the prevalence of facial pain indicating TMJ pain is $29.0 \%$ used the classification for depression disability and showed that severe depression found in a total of $69.6 \%$ of whom have facial pain and grade VI disability found in only $2.6 \%$ of the total of whom have facial pain and it has been found here that as the age increases the symptoms increases too and this is in agreement with previous studies. ${ }^{18-20}$

This survey consisted of 23 interrogatories that covered relevant symptoms and studied the subjective reactions to symptoms. In addition to joint sounds, the other symptoms assessed in TMD include headache, grinding, and clenching.

In Farsi et al.'s study, clicking was the most common sign of TMD clinically; and the absence of crepitus in children and adolescents is in harmony with similar findings published earlier. ${ }^{21}$

In one study, ${ }^{22} 34 \%$ of 80 dental cases described having recurring headaches; however, an increasing sample in other studies reported a prevalence between 12.5 and $24 \%{ }^{16,23,24}$

In Chuang's study for headache was $1654 \%$. It has been inferred that the prevalence of listed signs and symptoms of TMD will depend hugely on the ways of judgment. ${ }^{9}$

In this study, the prevalence of headache or migraine is $45.2 \%$, which is much higher than that of the study by Chuang, but sometimes many other conditions are correlated with headache, so its presence solely cannot be a measure of TMD.

In this study, difficulty or pain in mouth opening, in addition to headache, are lower in females than males which is opposite to the study by Chuang where there are headache and difficulty or pain in opening the mouth, which are symptoms that occur less commonly among males than females, which is correlated with temporomandibular dysfunction symptoms. ${ }^{7}$

It is worth noting that there is a difference in the total number in Table 1 (396) and Table 2 (392), this is explained by the reason that the four students (the difference) not answering the question that asked about the presence of facial pain. 
Prevalence of Temporomandibular Disorder in Jordan

\begin{tabular}{|c|c|c|c|c|c|c|}
\hline Authors & Year of publishing & Country & The sample & Sample age & How studied & Prevalence (\%) \\
\hline Akeel R, Al-Jasser N & 1999 & Saudi Arabia & 191 & $8-18$ & Physical examination & $\begin{array}{l}\text { Sign: } 41 \\
\text { Symptom: } 30\end{array}$ \\
\hline $\begin{array}{l}\text { Sonnesen I, Bakke M, } \\
\text { Solow B }\end{array}$ & 2000 & Denmark & 104 & $7-13$ & $\begin{array}{l}\text { Questionnaire, dental record } \\
\text { and physical examination }\end{array}$ & $34-39$ \\
\hline Farsi NM & 2003 & Saudi Arabia & 1976 & $3-15$ & $\begin{array}{l}\text { Questionnaire \& clinical } \\
\text { examination }\end{array}$ & 20.7 \\
\hline $\begin{array}{l}\text { Nassif NJ, Al-Salleeh T, } \\
\text { Al-admawi M }\end{array}$ & 2003 & Saudi Arabia & 523 & $18-25$ & $\begin{array}{l}\text { History \& physical } \\
\text { examination }\end{array}$ & 75 \\
\hline $\begin{array}{l}\text { Pedroni CR, Oliveira AS, } \\
\text { Guaratini MI }\end{array}$ & 2003 & Brazil & 50 & $19-25$ & $\begin{array}{l}\text { Questionnaire, and physical } \\
\text { examination }\end{array}$ & 68 \\
\hline $\begin{array}{l}\text { Jagger RG, Woolley SM, } \\
\text { Savio L }\end{array}$ & 2004 & United Kingdom & 140 & $16-65$ & $\begin{array}{l}\text { Questionnaire, and physical } \\
\text { examination }\end{array}$ & $\begin{array}{l}\text { Sign: 63, } \\
\text { Symptom: } 41\end{array}$ \\
\hline AS De Oliveira et al. & 2006 & Brazil & 2396 & $17-27$ & Questionnaire & 64.65 \\
\hline PF Weiss et al. & 2008 & USA & 32 & $1.5-17.2$ & $\begin{array}{l}\text { Questionnaire, and physical } \\
\text { examination }\end{array}$ & 53 \\
\hline B Bagis et al. & 2012 & Turkey & 243 & $14-59$ & $\begin{array}{l}\text { Questionnaire, and physical } \\
\text { examination }\end{array}$ & 92 \\
\hline
\end{tabular}

However, Bagis et al.'s study showed a very high prevalence of TMJ disease compared with the result of this study and that was exceeding the rate described in the study by Farsi et al., this could be explained by a relatively higher average age range as well as the type of the sample that was selected in there study who were patients referred to the prosthodontic department (Table 6). ${ }^{25}$

Finally, Weiss et al. measured the prevalence in arthritis patients where the gender distribution seems similar to this study, where he observed that the males were at a higher prevalence of TMJ disease. ${ }^{26}$

\section{ConcLusion}

Based on the results obtained, it can be concluded that:

- Data gathered by the survey questions recognized a nearly lower percentage of TMD in schoolchildren than most of the studies published in the literature

- Comparing with females, males with TMD had a higher disability, depression, and unspecific symptoms without and with pain.

\section{Recommendations}

At the end of the study, it was recommended that:

- Further studies were required to clarify the prevalence in other age groups.

- This age group needs some actions to prevent or treat TMD and decrease the pain, depression, and disability that resulted from it.

\section{References}

1. Farsi NM. Symptoms and signs of temporomandibular disorders and oral parafunctions among Saudi children. J Oral Rehabilitat 2003;30(12):1200-1208. DOI: 10.1111/j.1365-2842.2003.01187.x.

2. John MT, Dworkin SF, Mancld LF. Reliability of clinical temporomandibular disorder diagnoses. Pain 2005;118(1-2):61-69. DOI: 10.1016/j.pain.2005.07.018.

3. dowrkin SF, Huggins HH, LeResche L, et al. Epidemiology of signs and symptoms in TMD: clinical signs in cases and control. J Am Dent Associat 1990;102(3):273-281. DOI: 10.14219/jada.archive.1990.0043.

4. Pedroni CR, De oliveira AS, Guaratini MI. Prevalence study of signs and symptoms of temporomandibular disorders in university students. J Oral Rehabilitat 2003;30(3):283-289. DOI: 10.1046/j.13652842.2003.01010.x.

5. Akeel R, Al-Jasser N. Temporomandibular disorders in Saudi females seeking orthodontic treatment. J Oral Rehabilitat 1999;26(9):757-762. DOI: 10.1046/j.1365-2842.1999.00437.x.

6. Magnusson T, Egermark-Eriksson I, Carlsson GE. Four-year longitudinal study of mandibular dysfunction in children. Commun Dent Oral Epidemiol 1985;13(2):117. DOI: 10.1111/j.1600-0528.1985. tb01690.x.

7. Chuang SY. Incidence of temporomandibular disorders (TMDs) in senior dental students in Taiwan. J Oral Rehabilitat 2002;29(12):12061211. DOI: 10.1046/j.1365-2842.2002.00968.x.

8. Schmitter M, Rammelsberg P, Hassel A. The prevalence of signs and symptoms of temporomandibular disorders in very old subjects. J Oral Rehabilitat 2005;32(7):467-473. DOI: 10.1111/j.13652842.2005.01449.x.

9. Jagger RG, Woolley SM, Savio L. Signs and symptoms of temporomandibular disorders in ecuadorian Indians.J Oral Rehabilitat 2004;31(4):293-297. DOI: 10.1046/j.1365-2842.2003.01259.x.

10. Nassif NJ, Al-salleeh F, Al-admawi M. The prevalence and treatment needs of symptoms and signs of temporomandibular disorders among young adult males. J Oral Rehabilitat 2003;30(9):944-950. DOI: 10.1046/j.1365-2842.2003.01143.x.

11. Le Resche L, Saunders K, Von Korff MR, et al. Use of exogenous hormones and risk of temporomandibular disorder pain. Pain 1997;69(1):153-160. DOI: 10.1016/S0304-3959(96)03230-7.

12. Sonnesen L, Bakke M, Solow B. Malocclusion traits and symptoms and signs of temporomandibular disorders in children with severe malocclusion. Eur J Orthodon 1998;20(5):543-559. DOI: 10.1093/ ejo/20.5.543.

13. Henrikson T, Nilner M, Kurol J. TMD and the need for stomatognathic treatment in orthodontically treated and untreated girls. Eur J Orthodont 2000;22(3):283-292. DOI: 10.1093/ejo/22.3.283.

14. Nilner M. Epidemiological studies in TMD. In McNeill C, ed. Current controversies in temporomandibular disorders. Chicago: Quintessence; 1992. pp. 21-26.

15. Nekora-Azak A. Temporomandibular disorders in relation to female reproductive hormones: a literature review. J Prosthet Dent 2004;91(5):491-493. DOI: 10.1016/j.prosdent.2004.03.002.

16. Solberg WK, Woo MW, Houston JB. Prevalence of mandibular dysfunction in young adults. J Am Dent Associat 1979;98(1):25. DOI: 10.14219/jada.archive.1979.0008.

17. Schiffman EL, Fricton JR, Haley DP, et al. The prevalence and treatment needs of subjects with temporomandibular disorders. J Am Dent Associat 1990;120(3):295. DOI: 10.14219/jada.archive.1990.0059. 
18. Egermark-Eriksson I, Carlsson GE, Ingervall B. Prevalence of mandibular dysfunction and orofacial parafunction in 7, 11 and 15 year old Swedish children. Eur J Orthodont 1981;3(3):163. DOI: 10.1093/ ejo/3.3.163.

19. Riolo ML, Brandt MSD, Tenhave TR. Associations between occlusal characteristics and signs and symptoms of TMJ dysfunction in children and young adults. Am J Orthodont Dentofac Orthop 1987;92(6):467. DOI: 10.1016/0889-5406(87)90228-9.

20. Olsson M, Lindqvist B. Mandibular function before orthodontic treatment. Eur J Orthod 1992;14(1):61. DOI: 10.1093/ejo/14.1.61.

21. Farsi NM, Alamode N. The aetiology of TMJ in children and adolescent is considered a multifactorial in nature and has been related to trauma, malocclusion, and parafunctional habits. J Pediat Dentis 2000;10(1):57-62. DOI: 10.1046/j.1365-263x.2000.00164.x.

22. Magnusson T, Carlsson GE. Comparison between two groups of patients in respect of headaches and mandibular dysfunction. Swedish Dent J 1978;2(3):85.
23. Hansson T, Nilner M. A study of symptoms of diseases of the temporomandibular joint masticatory musculature and related structures. J Oral Rehabilitat 1975;2(4):313. DOI: 10.1111/j.13652842.1975.tb01532.x.

24. Rieder CE. The prevalence of mandibular dysfunction. Sex and age distribution of signs and symptoms related to mandibular dysfunction. J Prosthe Dentis 1983;50(1):81. DOI: 10.1016/00223913(83)90171-3.

25. Bagis B, Ayaz EA, Turgut $S$, et al. Gender difference in prevalence of signs and symptoms of temporomandibular joint disorders: a retrospective study on 243 consecutive patients. Int J Med Sci 2012;9(7):539-544. DOI: 10.7150/ijms.4474.

26. Weiss PF, Arabshahi B, Johnson A, et al. High prevalence of temporomandibular joint arthritis at disease onset in children with Juvenile idiopathic arthritis, as detected by magnetic resonance imaging but not by ultrasound. Arthrit Rheumat 2008;58(4):11891196. DOI: 10.1002/art.23401. 